\title{
Synthesis and Characterization of Birnessite and Cryptomelane Nanostructures in Presence of Hoffmeister Anions
}

\author{
Marcos A. Cheney, ${ }^{1}$ Robin Jose, ${ }^{2}$ Arghya Banerjee, ${ }^{3}$ Pradip K. Bhowmik, ${ }^{4}$ Shizhi Qian, ${ }^{5}$ \\ and Joseph M. Okoh ${ }^{1}$ \\ ${ }^{1}$ Department of Natural Sciences, University of Maryland Eastern Shore, Princess Anne, MD 21853, USA \\ ${ }^{2}$ Department of Chemistry, Rocky Mountain College, 1511 Poly Drive, Billings, MT 59102, USA \\ ${ }^{3}$ Department of Aerospace Engineering Sciences, University of Colorado at Boulder, 429 UCB, Boulder, CO 80309, USA \\ ${ }^{4}$ Department of Chemistry, University of Nevada Las Vegas, 4505 Maryland Parkway, Box 454003, Las Vegas, NV 89154-4003, USA \\ ${ }^{5}$ Department of Aerospace Engineering, Old Dominion University, ECSB 1309, Elkhorn Ave, Norfolk, VA 23529-0247, USA
}

Correspondence should be addressed to Shizhi Qian, sqian@odu.edu

Received 19 November 2008; Accepted 16 March 2009

Recommended by Sherine Obare

The effect of Hoffmeister anions $\mathrm{Cl}^{-}, \mathrm{SO}_{4}{ }^{2-}$, and $\mathrm{ClO}_{4}{ }^{-}$on the structure and morphology of birnessite and cryptomelane-type manganese dioxide nanostructures, produced by the reduction reaction of $\mathrm{KMnO}_{4}$ and $\mathrm{MnSO}_{4}$ in aqueous acidic media, was studied. The syntheses were based on the decomposition of aqueous $\mathrm{KMnO}_{4}$ in presence of $\mathrm{HCl}$ for birnessite-type and acidified $\mathrm{MnSO}_{4}$ for cryptomelane-type manganese dioxide under soft hydrothermal conditions. They were characterized using X-ray diffraction (XRD), transmission electron microscopy (TEM), and high-resolution transmission electron microscopy (HRTEM) techniques. XRD patterns show the formation of birnessite for the first synthesis and a mixture of cryptomelane and birnessitetypes $\mathrm{MnO}_{2}$ for the second synthesis. XRD data revealed that the Hoffmeister anions have a significant effect on the nanostructures of birnessite. The sulphate ion-treated birnessite has the smallest crystals, whereas the chloride ion-treated birnessite has the largest crystals. Their TEM and HRTEM studies revealed a transformation from nanoplatelet morphology for chloride-treated samples to nanofibrous morphology for sulphate-treated birnessite. For the cryptomelane nanostructures, Hoffmeister anions also show a profound effect on their crystalline structures as determined by XRD analyses revealing a transformation of the cryptomelane phase to birnessite phase of $\mathrm{MnO}_{2}$. This transformation is also supported by TEM and HRTEM studies.

Copyright (C) 2009 Marcos A. Cheney et al. This is an open access article distributed under the Creative Commons Attribution License, which permits unrestricted use, distribution, and reproduction in any medium, provided the original work is properly cited.

\section{Introduction}

The vast research in nanoscience concerns development of liquid-phase synthetic procedures for the manufacture of nanomaterials with various crystallite shapes and complex assemblies including single crystals, wires, helices, rods, tubes, and inorganic films [1]. However, the foundation of all the above syntheses was based on trial and error and thus lacks basic concepts and mechanistic principles that would allow preparation of nanomaterials with desired properties including size, shape, and morphology in a controlled way [1].

Layer and tunnel-structured materials have attracted considerable attention due to their industrial applications, such as catalysis, ion-sieves, and rechargeable batteries [2-4]. Birnessite is a layer-structured mineral containing edge-shared $\mathrm{MnO}_{6}$ octahedra with a $d$-spacing of ca. $7 \AA$, which renders mobility of interlayer cations without a structural change [5]. Birnessite-type manganese oxide is a two-dimensional (2D) layer-structure material and an important precursor for the synthesis of tunnel-structure manganese oxides [6]. It is formed by a regular distribution of $\mathrm{Mn}$ vacancies in the $\mathrm{MnO}$ crystal matrix, and the structure is generated by the removal of $\mathrm{Mn}$ atoms from the corners and faces in a doubled unit cell of $\mathrm{MnO}$ [1].

Since the early report of McKenzie [7] for preparing layer-structured brown birnessite with microscale structures, 
other synthetic processes include oxidation of $\mathrm{Mn}(\mathrm{II})$ in basic solution [8], redox reaction between $\mathrm{Mn}(\mathrm{II})$ and $\mathrm{MnO}_{4}{ }^{-}$[9], reduction of $\mathrm{MnO}_{4}{ }^{-}$using different routes such as sol-gel [10], reaction of $\mathrm{HCl}$ with $\mathrm{MnO}_{4}{ }^{-}$followed by cationic exchange, and by oxidation of $\mathrm{Mn}$ (II) using $\mathrm{O}_{2}, \mathrm{~K}_{2} \mathrm{~S}_{2} \mathrm{O}_{8}$, and $\mathrm{H}_{2} \mathrm{O}_{2}$. Nanowires of $\alpha-\mathrm{MnO}_{2}$ are also synthesized using coordinationpolymers [11-13]. Birnessite nanoparticles with hexagonal layer structure with dendritic morphology are synthesized based on the reduction of $\mathrm{KMnO}_{4}$ in dilute aqueous $\mathrm{H}_{2} \mathrm{SO}_{4}$ with initial stirring, followed by wet-aging and air drying [14]. More recently, birnessite has also been prepared by the electrochemical stimulation of $\mathrm{Mn}_{3} \mathrm{O}_{4}$ in $\mathrm{Na}_{2} \mathrm{SO}_{4}$ solution to be used as electrochemical supercapacitors $[15,16]$ and semiconductors [17]. Pillared birnessite nanosheets have been prepared by an ion exchange method [18]. Transition metal-doped birnessite has also been prepared from surfactant-free nonaqueous sol-gel routes [1]. Black birnessite with complex nanomorphology has been synthesized by converting brown birnessite through wet-aging at $7^{\circ} \mathrm{C}$ for 48 hours, overnight freezing, and lyophilization [19]. Nevertheless, birnessite structural details, crystal chemistry, and morphological prediction remain elusive.

Cryptomelane is one group of the octahedral molecular sieves family, which is known to contain a $2 \times 2$ tunnel structure and has been widely used in catalysis as well as in the electronic industry [20]. Due to the many potential applications of birnessite and cryptomelane nanoparticles, the methods for preparing them with desired micro- and nanostructure have been a subject of intensive study. For Cryptomelane type manganese oxide, on the other hand, there are a few synthetic processes which include oxidation of $\mathrm{Mn}(\mathrm{II})$ by $\mathrm{KMnO}_{4}, \mathrm{~K}_{2} \mathrm{~S}_{2} \mathrm{O}_{8}$, or $\mathrm{H}_{2} \mathrm{O}_{2}$ in acidic conditions under refluxing conditions [21], hydrothermal treatment of birnessite [22], and the sol-gel routes [23]. But again, the mentioned syntheses are on the basis of trial and error, and thus the basic concepts and mechanistic principles are not described. There is also paucity in literature on the effect of anions on the structure and morphology of birnessite and cryptomelane.

There is common knowledge of the effect of ions in all branches of colloids science. These effects range from mild to dramatic, and often times they are not well understood [24]. There are some reports in literature on the use of cations as doping agents in manganese oxides [1]. However, very little work is available on the effect of Hoffmeister anions on structure, morphology, and crystallinity of birnessite and cryptomelane-type $\mathrm{MnO}_{2}$ nanoparticles, which is the objective of this paper. We have chosen chloride, sulphate, and perchlorate anions as ions of interest because they represent the lower, middle, and upper end of the lyotropic Hoffmeister series and generally give strong Hoffmeister effect than cations [24]. The synthesis of birnessite was based on the reduction of $\mathrm{KMnO}_{4}$ in the presence of the corresponding anion as its potassium salt in an aqueous solution of the conjugate acid of the Hoffmeister anion. A similar approach was taken to synthesize cryptomelane where hot aqueous solution of $\mathrm{KMnO}_{4}$ was reduced by an aqueous solution of acidified manganese salt of the corresponding anion in the conjugate acid of the Hoffmeister anion.

\section{Experimental Method}

\subsection{Synthesis of Birnessite $\mathrm{MnO}_{2}$}

Effect of $\mathrm{Cl}^{-}$Ions. The synthesis of birnessite was divided into two steps: preparation of $\mathrm{KMnO}_{4}$ solution in the presence of $\mathrm{KCl}$ and slow dropwise addition of concentrated $\mathrm{HCl}$. The first step is composed of placing $3.16 \mathrm{~g}(0.02 \mathrm{~mol})$ of $\mathrm{KMnO}_{4}$ into a $50 \mathrm{~mL}$ volumetric flask followed by addition of nanopure water to the mark while shaking. The $\mathrm{pH}$ of the final solution was $\sim 6$. This solution was then placed into a $250 \mathrm{~mL}$ round-bottom flask after which $1.4910 \mathrm{~g}(0.02 \mathrm{~mol})$ of $\mathrm{KCl}$ was added while stirring and heating to $100^{\circ} \mathrm{C}$ (soft hydrothermal conditions) on a hot plate.

The second step involves the slow dropwise $(2 \mathrm{~mL} / \mathrm{min})$ addition of $0.02 \mathrm{~mol}$ of concentrated $\mathrm{HCl}(37.5 \%)$ via a dropping funnel over a period of two hours. The tip of the dropping funnel occupied $80 \%$ of the mouth of the roundbottom flask and so providing almost closed condition. After the addition of acid $(\mathrm{HCl})$, the reaction mixture was left to run for another four hours. The water level in the roundbottom flask was maintained at a constant level by periodic addition of nanopure water from a syringe. There was a white scale-like material seen on the walls of the round-bottom flask immediately after addition of the acid. This reaction mixture was then cooled to room temperature and aged at $7^{\circ} \mathrm{C}$ for 24 hours. The reaction mixture after aging was then centrifuged and decanted, and the solid washed several times until the wash water attained a constant $\mathrm{pH}$ of 6 . The reaction was not complete as indicated by a light violet color of the reaction mixture before centrifugation. The solids were then air-dried and characterized.

Effect of $\mathrm{SO}_{4}{ }^{2-}$ Ions. The above mentioned synthesis method used for studying the effect of $\mathrm{Cl}^{-}$was followed in this case as well to study the effect of $\mathrm{SO}_{4}{ }^{2-}$. In this experiment $\mathrm{KCl}$ and $\mathrm{HCl}$ were replaced with $3.49 \mathrm{~g}(0.0200 \mathrm{~mol})$ of $\mathrm{K}_{2} \mathrm{SO}_{4}$ and $1.92 \mathrm{~g}(0.0100 \mathrm{~mol})$ of $\mathrm{H}_{2} \mathrm{SO}_{4}$, respectively. After 6 hours, the reaction mixture was cooled to room temperature and aged as described above. There was very little precipitate formed in the reaction mixture compared to $\mathrm{KCl}$ above, and the solids did not settle at the bottom of the flask. Also, the color of the reaction mixture was intense purple. After the aging step, the reaction was centrifuged and washed till the $\mathrm{pH}$ of the rinse water attained a constant $\mathrm{pH}$ of 6 . The thin layer of material adsorbed to the walls of the reaction vessel was collected as well. During the washing stage, a white scale-like material appeared floating on the surface of the mixture. The solids collected after centrifugation were then air-dried and characterized.

Effect of $\mathrm{ClO}_{4}{ }^{-}$Ions. The synthetic method used for studying the effect of $\mathrm{Cl}^{-}$was followed here as well. In this experiment $\mathrm{KCl}$ and $\mathrm{HCl}$ were replaced with $2.81 \mathrm{~g}(0.0200 \mathrm{~mol})$ of $\mathrm{KClO}_{4}$ and $6.69 \mathrm{~g}(0.0400 \mathrm{~mol})$ of $\mathrm{HClO}_{4}$, respectively. After 
6 hours of reaction under soft hydrothermal conditions, the reaction mixture was cooled to room temperature and aged as described above. There was much more of the black precipitate formed compared to the synthesis in the presence of $\mathrm{SO}_{4}{ }^{2-}$ anion, and the solids formed completely settled at the bottom of the flask. The supernatant liquid was colorless indicating that the reaction was completed. The solids were then centrifuged, washed until the wash water attained a constant $\mathrm{pH}$ of 5 , then air-dried and characterized.

\subsection{Synthesis of Cryptomelane $\mathrm{MnO}_{2}$}

Effect of $\mathrm{Cl}^{-}$. The synthesis of cryptomelane was divided into two steps: preparation of $\mathrm{KMnO}_{4}$ solution followed by slow dropwise addition of acidified $(\mathrm{HCl}) \mathrm{MnCl}_{2}$ solution. The first step is composed of placing $2.76 \mathrm{~g}(0.0175 \mathrm{~mol})$ of $\mathrm{KMnO}_{4}$ into a $50 \mathrm{~mL}$ volumetric flask followed by addition of nanopure water to the mark while shaking. The $\mathrm{pH}$ of the final solution was $\sim 6$. This solution was then placed into a $250 \mathrm{~mL}$ round-bottom flask and heated to $65^{\circ} \mathrm{C}$ (soft hydrothermal conditions) on a hot plate under stirring.

The second step involves the slow dropwise $(2 \mathrm{~mL} / \mathrm{min})$ addition of a solution of $0.025 \mathrm{~mol}(4.95 \mathrm{~g})$ of $\mathrm{MnCl}_{2}$ • $4 \mathrm{H}_{2} \mathrm{O}$ in $\mathrm{HCl}(2 \mathrm{M}, 9.72 \mathrm{~g}$ in $50 \mathrm{~mL}$ water), while stirring, via a separatory funnel over a period of two hours. The tip of the separatory funnel occupied $80 \%$ of the mouth of the round-bottom flask and so providing almost closed condition. Solids formed immediately upon addition of acidified $\mathrm{MnCl}_{2}$. The temperature of the reaction mixture was increased to $85^{\circ} \mathrm{C}$ and maintained for 20 minutes. The water level in the round-bottom flask was maintained at a constant level by periodic addition of nanopure water from a syringe. The reaction mixture was then cooled to room temperature and aged at $7^{\circ} \mathrm{C}$ for 48 hours. The mixture after aging was then centrifuged, decanted and the solid washed several times until the wash water attained a constant $\mathrm{pH}$ of 4. The $\mathrm{pH}$ of the first rinse water was $\sim 1$, and the washing continued till the rinse water attained a constant $\mathrm{pH}$ of 4 . The solids after the rinse step showed a clay-like consistency. The reaction was complete as indicated by a colorless of the reaction mixture before centrifugation. The solids were then air-dried and characterized.

Effect of $\mathrm{SO}_{4}{ }^{2-}$ Ions. The procedure used above for studying the effect of $\mathrm{Cl}^{-}$was used here. Here $\mathrm{MnCl}_{2}$ and $\mathrm{HCl}$ were replaced by $4.23 \mathrm{~g}(0.0250 \mathrm{~mol})$ of $\mathrm{MnSO}_{4}$ and $10.15 \mathrm{~g}$ $(2.00 \mathrm{M})$ of $\mathrm{H}_{2} \mathrm{SO}_{4}$, respectively. The reaction was complete as indicated by the colorless supernatant liquid at the end of the reaction. After the aging step, the mixture was centrifuged; the solids rinsed as described above, air-dried, and characterized.

Effect of $\mathrm{ClO}_{4}{ }^{-}$. The procedure used for studying the effect of $\mathrm{Cl}^{-}$was used here. Here $\mathrm{MnCl}_{2}$ and $\mathrm{HCl}$ were replaced by $6.35 \mathrm{~g}(0.0250 \mathrm{~mol})$ of $\mathrm{MnClO}_{4}$ and $16.74 \mathrm{~g}(2.00 \mathrm{M})$ of $\mathrm{HClO}_{4}(60.0 \%)$, respectively. The reaction rate was not as fast compared to the chloride or sulfate reaction as indicated by the slow disappearance of the permanganate purple color. However, the reaction was complete as indicated by the colorless transparent liquid observed at the end of the reaction. After the aging step, the mixture was centrifuged, and the solids rinsed as described above. During the rinse step, there was some scale-like white material floating on the surface of the wash liquid. The consistency of the isolated material was more like birnessite than the clay-like consistency of cryptomelane. Isolated product was then airdried and characterized.

2.3. Characterization Techniques. The manganese oxides were characterized by X-ray powder diffraction (XRD) using a PANalytical X'Pert PRO X-ray diffractometer with a $\mathrm{CuK}_{\alpha}$ radiation $(40 \mathrm{KV}, 40 \mathrm{~mA})$ and an $\mathrm{X}^{\prime}$ Celerator solid state detector. The samples were prepared on silicon sample holder by suspending the sample in ethanol to form slurry. The patterns were recorded at room temperature with stepsizes of $0.008^{\circ}, 2 \theta$, and 50 seconds per step.

Transmission electron microscopy (TEM) and highresolution transmission electron microscopy (HRTEM) images were obtained with a Tecnai $G^{2}$ F30 S-Twin TEM instrument. The TEM operates at $300 \mathrm{KV}$ using a field emission gun in Schottky mode as an electron source. The samples for TEM analysis were prepared by placing $3 \mathrm{mg}$ of the air-dried solid manganese oxide in $10 \mathrm{~mL}$ of 2-propanol, and sonication for 5 minutes for homogeneity. One drop of the slurry was deposited on a holey-carbon-coated copper grid for analysis.

\section{Results and Discussion}

In the birnessite synthesis, the effect of Hoffmeister series was evident in the extent of reaction/product yield. Sulfate which is at the left end of the lyotropic Hoffmeister series was less effective compared to chloride which is in the middle of the series which was less effective than perchlorate which is in the right end of the series in reducing potassium permanganate. In the cryptomelane synthesis it was noted that the rate of reaction is affected by anions as sulfate was faster reducing than chloride which was faster than perchlorate. Though the reduction was complete in the cases of all three anions, nature of the product varied from a clay-like consistency to granular form suggesting a structure and morphology change.

\subsection{X-ray Powder Diffraction}

3.1.1. Birnessite Structure. Figure 1 shows the XRD patterns for birnessite material synthesized in the presence of chloride (a), perchlorate (b), and sulfate (c) ions. The observed diffraction patterns were then compared with the JCPDSICDD File Card $[25,26]$ to confirm the proper phase formation of the birnessite structure. The peaks of the diffraction pattern are identified to originate from (001), (002), (111), and (005) reflections. This pattern closely reflects the monoclinic crystal structure with $\mathrm{C} 2 / \mathrm{m}$ space group [25]. It has been observed that the peak intensity and sharpness is the maximum for the samples synthesized 


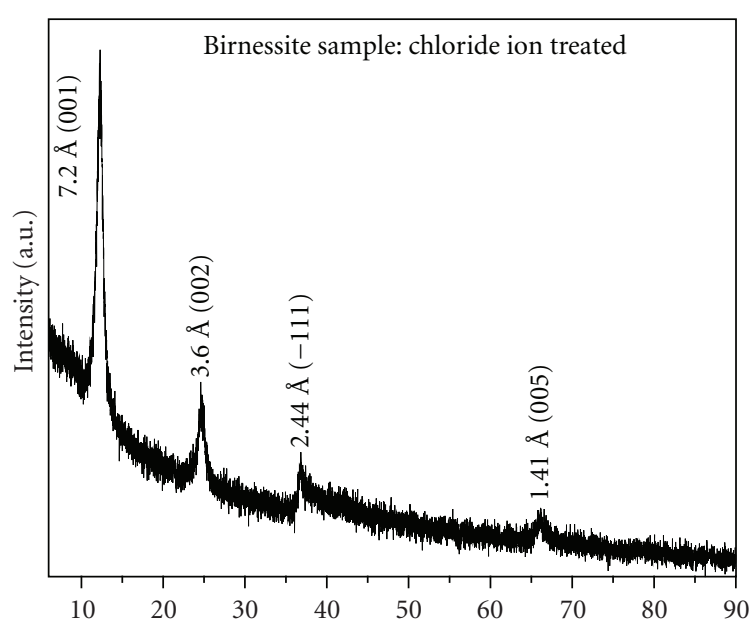

(a)

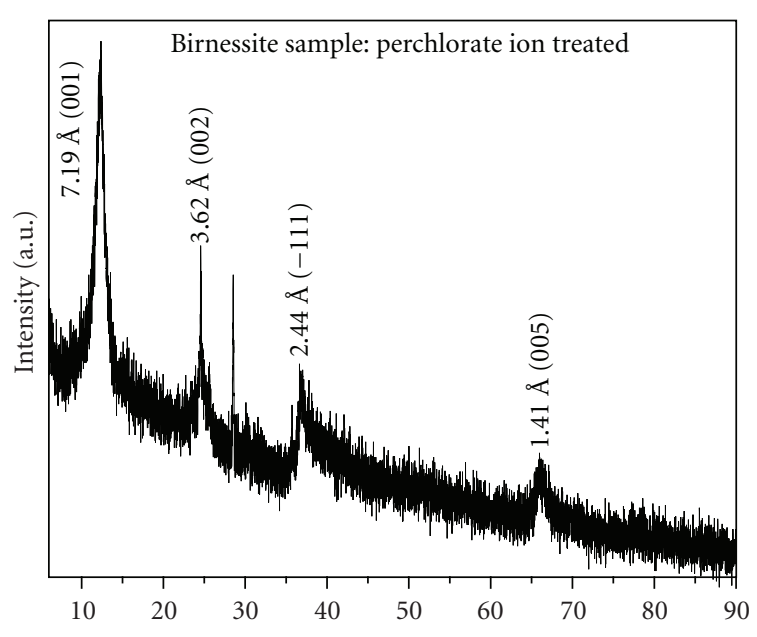

(b)

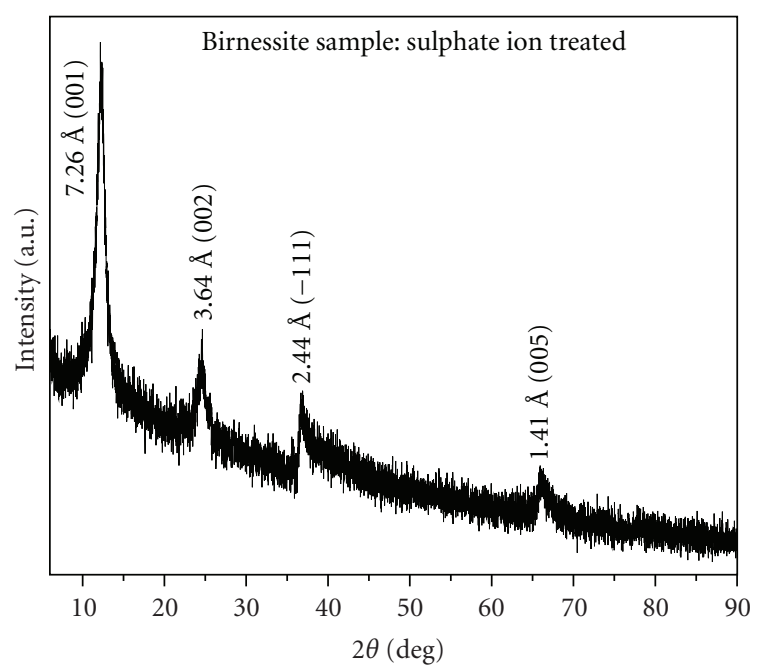

(c)

FIGURE 1: XRD spectra of (a) $\mathrm{Cl}^{-}$- treated birnessite nanomaterial, (b) $\mathrm{ClO}_{4}{ }^{-}$- treated birnessite nanomaterial, and (c) $\mathrm{SO}_{4}{ }^{-2}$ - treated birnessite nanomaterial.

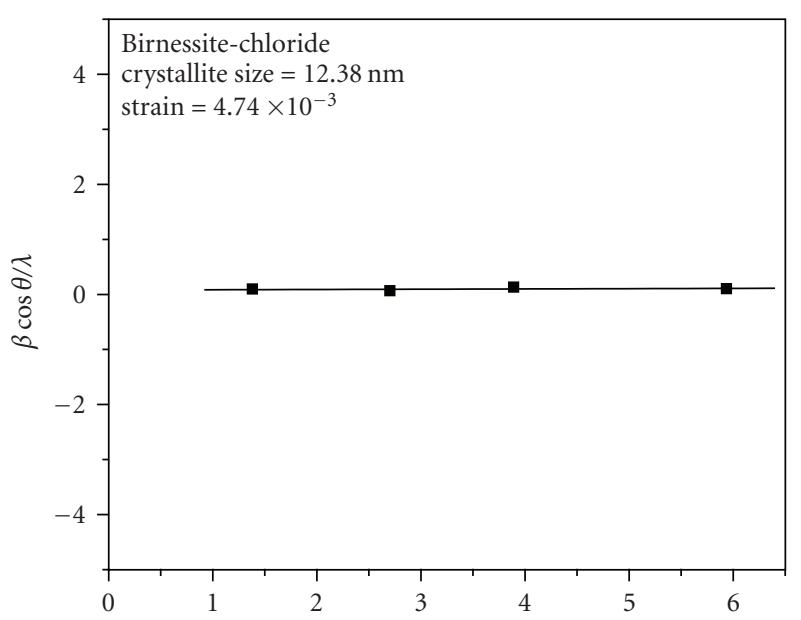

(a)

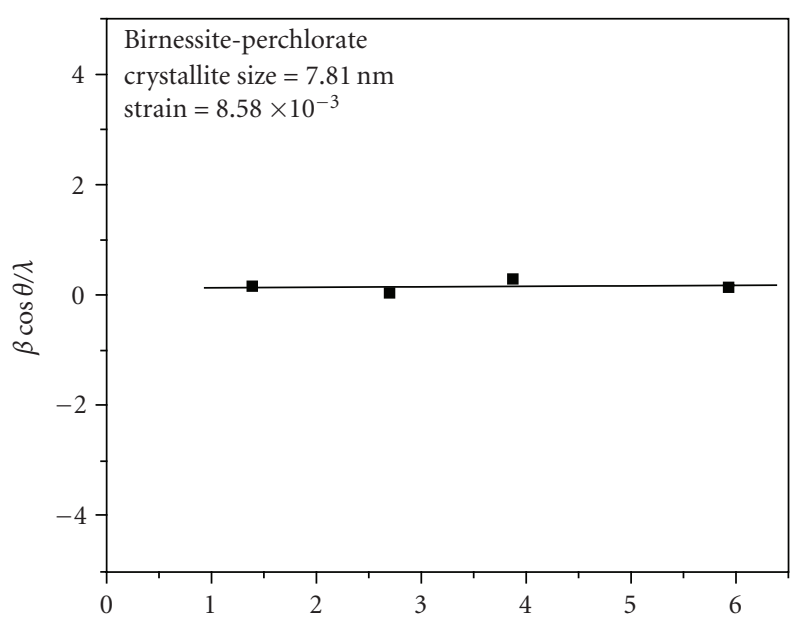

(b)

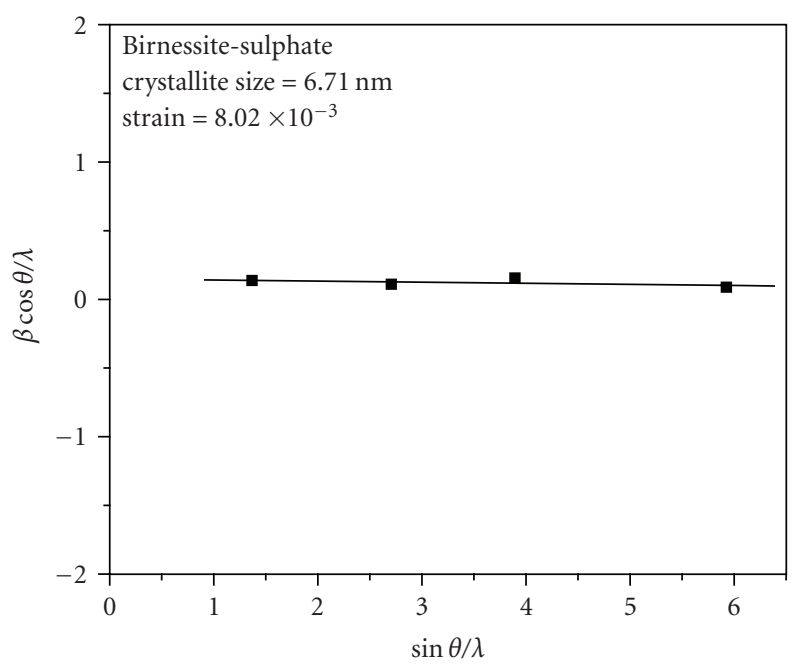

(c)

FIGURE 2: Size-Strain analyses of birnessite samples treated under (a) $\mathrm{Cl}^{-}$, (b) $\mathrm{ClO}_{4}{ }^{-}$, and (c) $\mathrm{SO}_{4}{ }^{-2}$ ions. The size-strain data are obtained from the corresponding XRD data furnished in Figure 1. 
in the presence of chloride ions, whereas these values are lesser for the birnessite sample synthesized in the presence of sulphate and perchlorate ions. It is wellknown that broader diffraction peak with lesser intensity reflects the nanocrystalline (nanosize) nature of a material [27]. Therefore, a close comparison of Figures 1(a), 1(b), and 1(c) reveals that sulphate ion-treated birnessite samples are more nanocrystalline in nature than chloride iontreated birnessite samples, whereas perchlorate ion-treated samples are intermediate in nature. These arguments are also supported by the size-strain analyses as well as from the electron microscopic measurements, described in the following sections.

The information on strain and the crystallite size of the deposited material could be obtained from the full-widthat-half-maximum (FWHM) of the diffraction peaks. The FWHM's ( $\beta$ 's) can be expressed as a linear combination of the contributions from the strain $(\varepsilon)$ and the crystallite size $(L)$ through the following relation [28]:

$$
\frac{\beta \cos \theta}{\lambda}=\frac{1}{L}+\frac{\varepsilon \sin \theta}{\lambda},
$$

where $\lambda$ is the $\mathrm{X}$-ray wavelength $\left(\mathrm{Cu}-\mathrm{K}_{\alpha}=1.5406 \AA\right)$ used. A plot of $\beta \cos \theta / \lambda$ versus $\sin \theta / \lambda$ will be a straight line, the intercept of which at $y$-axis will carry the information of the crystallite size and slope will give the strain generated within the crystal. Figures 2(a), 2(b), and 2(c) represent the $\beta \cos \theta / \lambda$ versus $\sin \theta / \lambda$ graphs corresponding to the XRD data furnished in Figures 1(a), 1(b), and 1(c), respectively. The crystallite size and strain are calculated to be $12.38 \mathrm{~nm}$ and $4.74 \times 10^{-3}$, respectively, for birnessite samples synthesized in the presence of chloride ions. Similarly, for perchlorate- and sulphate-treated samples these values are $7.81 \mathrm{~nm}, 8.58 \times 10^{-3}$ and $6.71 \mathrm{~nm}, 8.02 \times 10^{-3}$, respectively. These values indicate that sulphate-treated samples are more nanocrystalline in nature than chloride-treated samples. Also nanocrystalline materials suffer from internal strain as depicted by the higher values of strain in sulphate- and perchlorate-treated samples.

3.1.2. Cryptomelane Structure. The diffraction peaks of cryptomelane formed in the current study are shown in Figure 3 in the presence of sulfate (a), chloride (b), and perchlorate (c) ions. It has been observed from the figures that there is a significant variation in the crystal structure of the material when treated with different ions. Figure 3(a) shows typical cryptomelane-like pattern having tetragonal crystal structure with I4 m space group [26]. Figure 3(b) shows an intermediate pattern between cryptomelane and birnessite structure. As shown in the figure, asterisk- $(*)$ marked peaks are arising from birnessite structure. A broad (001) birnessite peak is started to appear along with some smaller birnessite peaks, for example, (111), (113), and (020). The cryptomelane peaks, which are significantly intense in Figure 3(a), are now suppressed considerably due to the phase transformation. On the other hand, Figure 3(c) resembles more like a birnessite pattern, with cryptomelane peaks being suppressed further. This indicates that Hoffmeister anions have significant effect on the phase transformation of cryptomelane to birnessite crystal structure. These results are further evidenced from the transmission electron microscopic images described in the following sections.

\subsection{TEM Studies}

3.2.1. Birnessite Materials. TEM micrographs for birnessite samples treated under various ionic conditions are shown in Figures 4(a), 4(b), and 4(c). Insets represent the corresponding HRTEM images. Figure 4(a) corresponds to the birnessite sample synthesized under $(\mathrm{KCl})$ chloride ions. The figure shows two-dimensional nanoplatelet structure with formation of some nanobelts out of the plate structure. The average dimension of the nanobelts is around $12-15 \mathrm{~nm}$. The HRTEM image shown in the inset supports this observation showing the formation of a nanobelt out of the plate structure. Figure 4(b) and its inset show the TEM and HRTEM images of perchlorate-treated birnessite samples, respectively. These figures depict the transformation of the nanobelts toward partial nanofibrous morphology with average dimension lowering to $8-10 \mathrm{~nm}$. For sulphate-treated birnessite samples (cf. Figure 4(c) and the inset), the morphology becomes completely nanofibrous in nature with average fiber-dimension further lowered to 6-8 nm. This trend of ionic effect on the dimension and morphology of the birnessite samples is also supported by the size-strain analyses discussed in the earlier section (cf. Section 3.1, Figure 2), where it is observed that sulphatetreated samples have the least crystallite size $(\sim 7 \mathrm{~nm})$ and chloride-treated samples have the highest crystallite size (12 nm).

3.2.2. Cryptomelane Materials. Figures 5(a), 5(b), and 5(c) are the TEM micrographs for cryptomelane materials synthesized under sulphate, chloride, and perchlorate ions, respectively. Insets show the corresponding HRTEM images. Figure 5(a) shows the typical nanorod-like cryptomelane $\mathrm{MnO}_{2}$ structure, treated under sulphate ions, with average diameter and length around $20 \mathrm{~nm}$ and $100 \mathrm{~nm}$, respectively. Inset shows HRTEM image of the nanorods. Highly oriented atomic planes are clearly visible, indicating nanocrystalline nature of the structure. Figure 5(b) shows TEM image of chloride ion-treated $\mathrm{MnO}_{2}$ nanostructure. In this case, the nanorods appear to be elongated along the length. Also the diameters of the nanorods are decreased. The average length and diameter are found to be around $300 \mathrm{~nm}$ and $15 \mathrm{~nm}$, respectively. HRTEM image in the inset shows highly oriented atomic planes of the nanorod indicating singly crystalline nature of the rods. Also, the birnessite phase and respective morphology can also be seen in this TEM image as hexagonal spheres supporting the XRD results in Figure 3(b). The birnessite spheres have diameters in the order of $100 \mathrm{~nm}$. From the XRD and TEM data, we observe that this particular synthesis is novel because it involves two competing opposite reactions in the same system and thus can be divided 


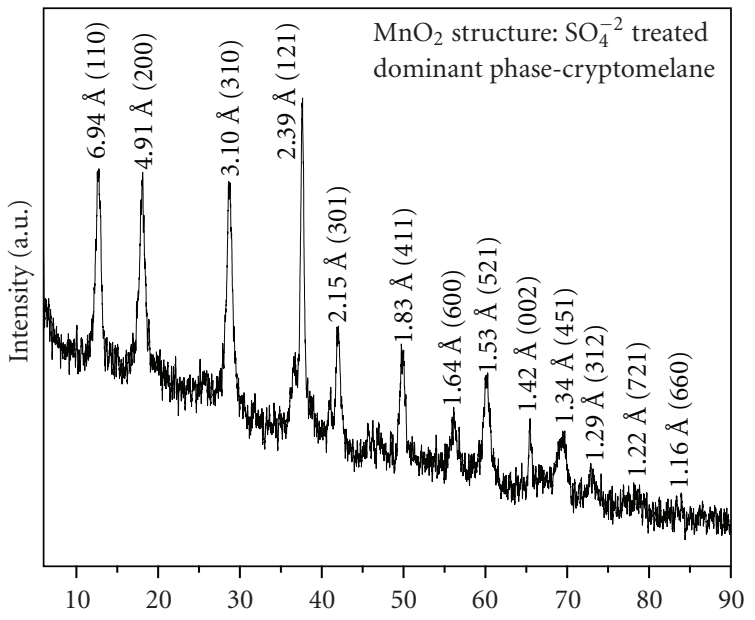

(a)

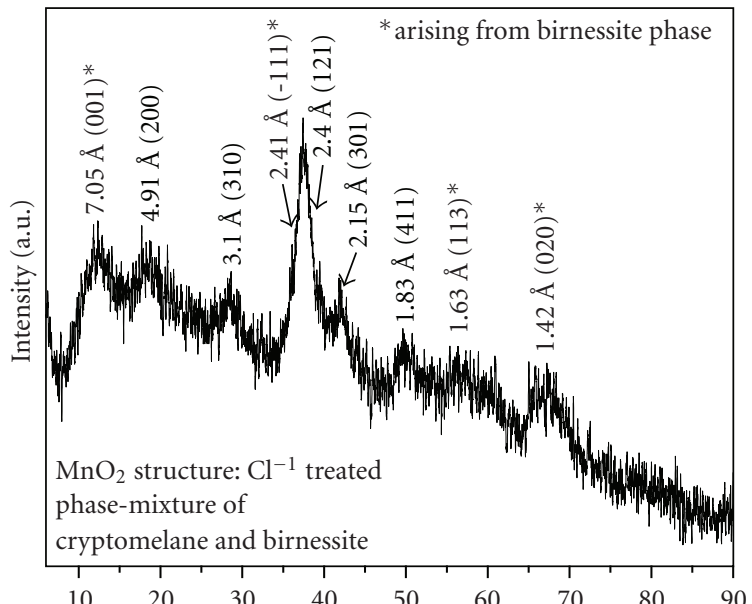

(b)

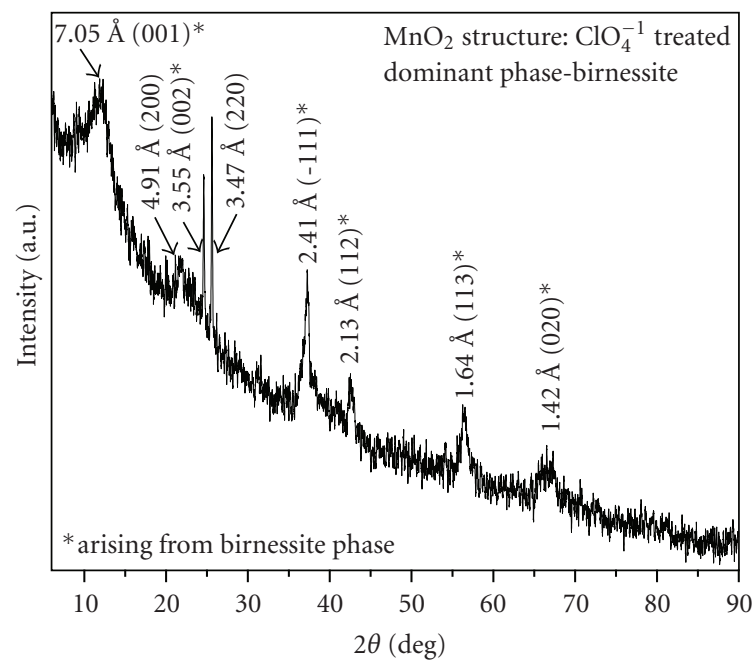

(c)

FigURE 3: XRD patterns of $\mathrm{MnO}_{2}$ nanostructures showing (a) a dominant cryptomelane phase under $\mathrm{SO}_{4}{ }^{-2}$ treatment, (b) a mixed phase of cryptomelane and birnessite under $\mathrm{Cl}^{-}$treatment, and (c) a dominant birnessite phase under $\mathrm{ClO}_{4}{ }^{-}$treatment.

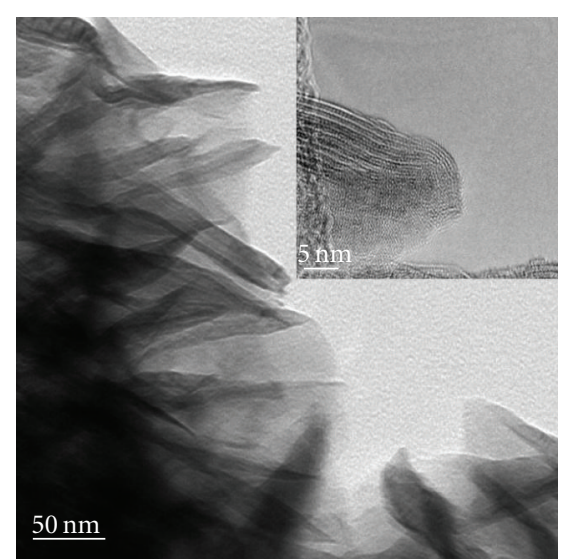

(a)

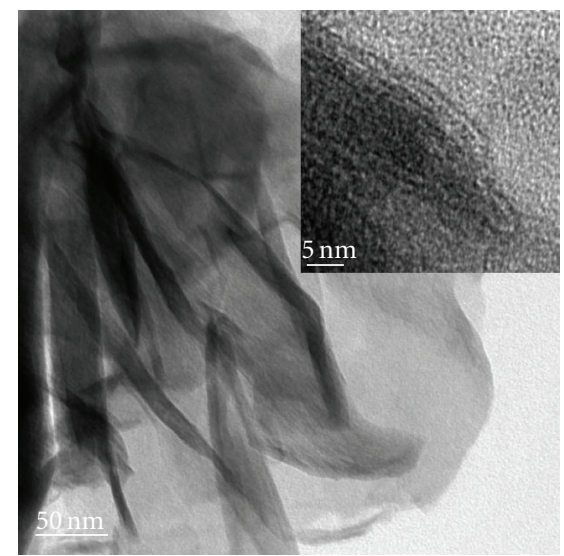

(b)

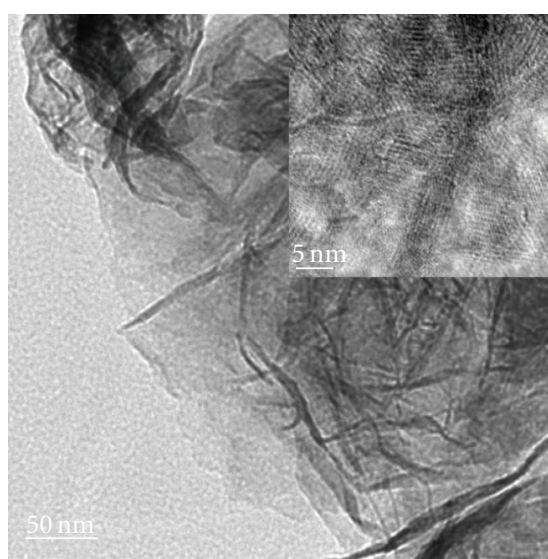

(c)

FIGURE 4: TEM micrographs of (a) $\mathrm{Cl}^{-}$, treated birnessite $\mathrm{MnO}_{2}$ nanostructure, (b) $\mathrm{ClO}_{4}{ }^{-}$, treated birnessite $\mathrm{MnO}_{2}$ nanostructure, and (c) $\mathrm{SO}_{4}{ }^{-2}$-treated birnessite $\mathrm{MnO}_{2}$ nanostructure. Insets show the corresponding HRTEM images. 


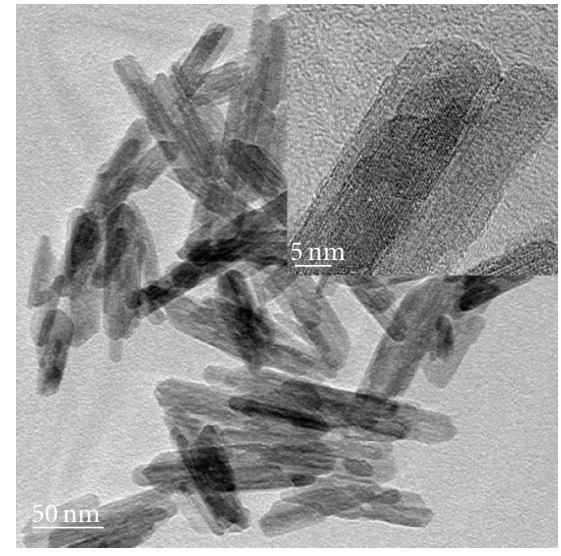

(a)

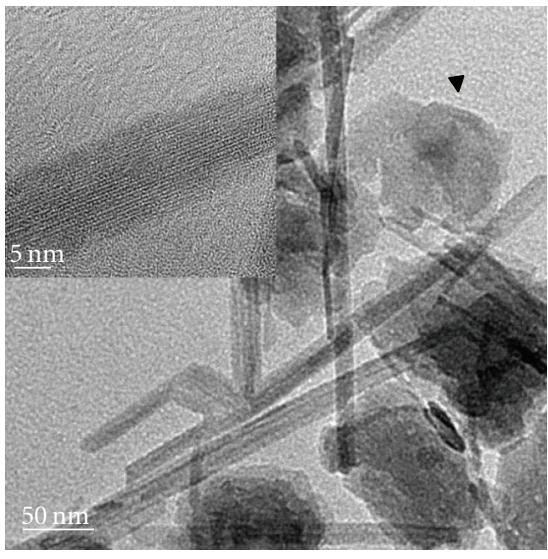

(b)

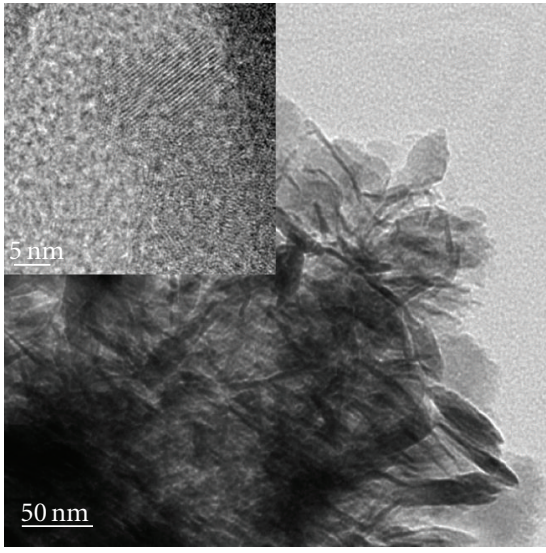

(c)

FIGURE 5: TEM micrographs of (a) $\mathrm{SO}_{4}{ }^{-2}$-treated cryptomelane $\mathrm{MnO}_{2}$ nanostructure, (b) $\mathrm{Cl}^{-}$, treated mixed phase cryptomelane and birnessite $\mathrm{MnO}_{2}$ nanostructure, and (c) $\mathrm{ClO}_{4}{ }^{-}$-treated dominant birnessite $\mathrm{MnO}_{2}$ nanostructure. Insets show the corresponding HRTEM images.

into three steps: formation of cryptomelane by oxidation, formation of birnessite by reduction, and interconversion of cryptomelane to birnessite. The formation of cryptomelane is by the oxidation of $\mathrm{Mn}$ (II) to $\mathrm{Mn}$ (IV) by permanganate at $\mathrm{pH}$ 6. The formation of birnessite is via reduction of $\mathrm{Mn}(\mathrm{VII})$ (from permanganate) to $\mathrm{Mn}$ (IV) by $\mathrm{HCl}$ at $\mathrm{pH}$ 3. Note that the $\mathrm{Cl}^{-}$ions present at $\mathrm{pH} 6$, due to the use of $\mathrm{MnCl}_{2}$, do not participate in the reaction until the $\mathrm{pH}$ is lowered, and thus the formation of the needles of cryptomelane is entirely due to the oxidation of $\mathrm{Mn}(\mathrm{II})$. The transformation of cryptomelane to birnessite is both, simultaneously, a chemical process and a physical process: the first guided by the redox reaction between $\mathrm{MnO}_{4}{ }^{-}$, $\mathrm{Mn}(\mathrm{II})$ and $\mathrm{Cl}^{-}$, and the second guided by flexibility in the developmental process and the osmotic pressure. A distortion in the development of the subunits due to the anions present during synthesis promotes either needle-like or curved sheet morphologies both of which can be seen in TEM images. Figure 5(c) represents the TEM image of perchlorate-treated $\mathrm{MnO}_{2}$ nanomaterials. From the image, it appears that the morphology of the material has transformed to nanofibrous structure which more resembles to birnessite $\mathrm{MnO}_{2}$, as shown in Figure 4(c). The average dimension of the nanofibers is calculated to be around $8 \mathrm{~nm}$. Inset shows the HRTEM image of it. These images clearly supports the findings obtained in XRD data indicating that the Hoffmeister anions have profound effect on the phase transformation of $\mathrm{MnO}_{2}$ nanostructures from cryptomelane phase to birnessite phase for sulphate to perchlorate treatments. The chemistry and detailed mechanism behind this phase transformation at low $\mathrm{pH}$ is under investigation. However, we speculate that the formation of these intriguing morphologies may be due to structural control of crystal growth guided by osmotic pressure. The methods reported here are highly reproducible if the synthetic parameters such as temperature, stirring rate and speed of addition of one reactant into another are strictly controlled.

\section{Conclusion}

Birnessite structural details, crystal chemistry, and morphological prediction remain an enigma. This is due, in part, to the fact that the foundation of most of the synthesis mentioned in literature was based on trial and error and thus lack-basic concepts and mechanistic principles that would allow preparation of nanomaterials with desired size, shape, and morphology in a control way.

A new understanding of the influence of the counter ions on the morphology of the produced nanomaterial is provided by studying the effect of Hoffmeister anions $\mathrm{Cl}^{-}, \mathrm{SO}_{4}^{-2}$, and $\mathrm{ClO}_{4}^{-}$on the structure and morphology of birnessite and cryptomelane-type manganese dioxide nanostructures. The Hoffmeister anion effect is first seen in the production of birnessite with different morphologies and crystallite sizes. The same effect was observed in the production of cryptomelane where a mixture of cryptomelane and birnessite was obtained under $\mathrm{MnCl}_{2}$ and $\mathrm{HCl}$ involving two competing opposite redox reactions. The conversion of cryptomelane to birnessite is accomplished by controlling the redox reaction between $\mathrm{MnO}_{4}^{-}, \mathrm{Mn}(\mathrm{II})$, and $\mathrm{HCl}$.

\section{Acknowledgment}

This work is supported, in part, by a visiting funding to SQ from the key laboratory of the Three Gorges Reservoir Region's Eco-Environment, Ministry of Education, Chongqing University, China.

\section{References}

[1] I. Djerdj, D. Arčon, Z. Jagličić, and M. Niederberger, "Nonaqueous synthesis of metal oxide nanoparticles: short review and doped titanium dioxide as case study for the preparation of transition metal-doped oxide nanoparticles," Journal of Solid State Chemistry, vol. 181, no. 7, pp. 1571-1581, 2008. 
[2] A. R. Armstrong and P. G. Bruce, "Synthesis of layered $\mathrm{LiMnO}_{2}$ as an electrode for rechargeable lithium batteries," Nature, vol. 381, no. 6582, pp. 499-500, 1996.

[3] S. L. Brock, N. Duan, Z. R. Tian, O. Giraldo, H. Zhou, and S. L. Suib, "A review of porous manganese oxide materials," Chemistry of Materials, vol. 10, no. 10, pp. 2619-2628, 1998.

[4] Q. Feng, H. Kanoh, and K. Ooi, "Manganese oxide porous crystals," Journal of Materials Chemistry, vol. 9, no. 2, pp. 319333, 1999.

[5] R. Ma, Y. Bando, L. Zhang, and T. Sasaki, "Layered $\mathrm{MnO}_{2}$ nanobelts: hydrothermal synthesis and electrochemical measurements," Advanced Materials, vol. 16, no. 11, pp. 918-922, 2004.

[6] C. Calvert, R. Joesten, K. Ngala, et al., "Synthesis, characterization, and rietveld refinement of tungsten-framework-doped porous manganese oxide (K-OMS-2) material," Chemistry of Materials, vol. 20, no. 20, pp. 6382-6388, 2008.

[7] R. M. McKenzie, "The synthesis of birnessite, cryptomelane, and some other oxides and hydroxides of manganese," Mineralogical Magazine, vol. 38, pp. 493-502, 1971.

[8] D. C. Golden, C. C. Chen, and J. B. Dixon, "Synthesis of todorokite," Science, vol. 231, no. 4739, pp. 717-719, 1986.

[9] J. Luo and S. L. Suib, "Formation and transformation of mesoporous and layered manganese oxides in the presence of longchain ammonium hydroxides," Chemical Communications, no. 11, pp. 1031-1032, 1997.

[10] J. Cai, J. Liu, and S. L. Suib, "Preparative parameters and framework dopant effects in the synthesis of layer-structure birnessite by air oxidation," Chemistry of Materials, vol. 14, no. 5, pp. 2071-2077, 2002.

[11] T. D. Xiao, E. R. Strutt, M. Benaissa, H. Chen, and B. H. Kear, "Synthesis of high active-site density nanofibrous $\mathrm{MnO}_{2}$ base materials with enhanced permeabilities," Nanostructured Materials, vol. 10, no. 6, pp. 1051-1061, 1998.

[12] Y. Xiong, Y. Xie, Z. Li, and C. Wu, "Growth of well-aligned $\gamma-\mathrm{MnO}_{2}$ monocrystalline nanowires through a coordinationpolymer-precursor route," Chemistry: A European Journal, vol. 9, no. 7, pp. 1645-1651, 2003.

[13] X. Wang and Y. Li, "Selected-control hydrothermal synthesis of $\alpha$ - and $\beta-\mathrm{MnO}_{2}$ single crystal nanowires," Journal of the American Chemical Society, vol. 124, no. 12, pp. 2880-2881, 2002.

[14] M. A. Cheney, P. K. Bhowmik, S. Moriuchi, M. Villalobos, S. Qian, and S. W. Joo, "The effect of stirring on the morphology of birnessite nanoparticles," Journal of Nanomaterials, vol. 2008, Article ID 168716, 9 pages, 2008.

[15] S. Komaba, A. Ogata, and T. Tsuchikawa, "Enhanced supercapacitive behaviors of birnessite," Electrochemistry Communications, vol. 10, no. 10, pp. 1435-1437, 2008.

[16] L. Athouël, F. Moser, R. Dugas, O. Crosnier, D. Bélanger, and T. Brousse, "Variation of the $\mathrm{MnO}_{2}$ birnessite structure upon charge/discharge in an electrochemical supercapacitor electrode in aqueous $\mathrm{Na}_{2} \mathrm{SO}_{4}$ electrolyte," The Journal of Physical Chemistry C, vol. 112, no. 18, pp. 7270-7277, 2008.

[17] N. Larabi-Gruet, S. Peulon, A. Lacroix, and A. Chaussé, "Studies of electrodeposition from $\mathrm{Mn}$ (II) species of thin layers of birnessite onto transparent semiconductor," Electrochimica Acta, vol. 53, no. 24, pp. 7281-7287, 2008.

[18] B. Ma, W. Hou, Y. Han, R. Sun, and Z.-H. Liu, "Exfoliation reaction of birnessite-type manganese oxide by a hostguest electrostatic repulsion in aqueous solution," Solid State Sciences, vol. 10, no. 2, pp. 141-147, 2008.

[19] M. A. Cheney, P. K. Bhowmik, S. Qian, S. W. Joo, W. Hou, and J. M. Okoh, "A new method of synthesizing black birnessite nanoparticles: from brown to black birnessite with nanostructures," Journal of Nanomaterials, vol. 2008, Article ID 763706, 8 pages, 2008.

[20] S. L. Suib, "Microporous manganese oxides," Current Opinion in Solid State and Materials Science, vol. 3, no. 1, pp. 63-70, 1998.

[21] J. C. Villegas, L. J. Garces, S. Gomez, J. P. Durand, and S. L. Suib, "Particle size control of cryptomelane nanomaterials by use of $\mathrm{H}_{2} \mathrm{O}_{2}$ in acidic conditions," Chemistry of Materials, vol. 17, no. 7, pp. 1910-1918, 2005.

[22] L. D. Conde and S. L. Suib, "Catalyst nature and frequency effects on the oligomerization of methane via microwave heating," The Journal of Physical Chemistry B, vol. 107, no. 15, pp. 3663-3670, 2003.

[23] S. Ching, J. L. Roark, N. Duan, and S. L. Suib, "Sol-gel route to the tunneled manganese oxide cryptomelane," Chemistry of Materials, vol. 9, no. 3, pp. 750-754, 1997.

[24] E. Leontidiz, "Hoffmeister anion effects on surfactant selfassembly and the formation of mesoporous solids," Current Opinion in Colloid \& Interface Science, vol. 7, no. 1-2, pp. 8191, 2002.

[25] Joint Committee on Powder Diffraction standards/International Centre for Diffraction Data (JCPDS-ICDD), File Card no. 80-1098.

[26] Joint Committee on Powder Diffraction standards/International Centre for Diffraction Data (JCPDS-ICDD), File Card no. 72-1982.

[27] B. D. Cullity, Elements of X-Ray Diffraction, Addison-Wesley, Reading, Mass, USA, 1978.

[28] S. B. Qadri, E. F. Skelton, D. Hsu, et al., "Size-induced transition-temperature reduction in nanoparticles of $\mathrm{ZnS}$," Physical Review B, vol. 60, no. 13, pp. 9191-9193, 1999. 

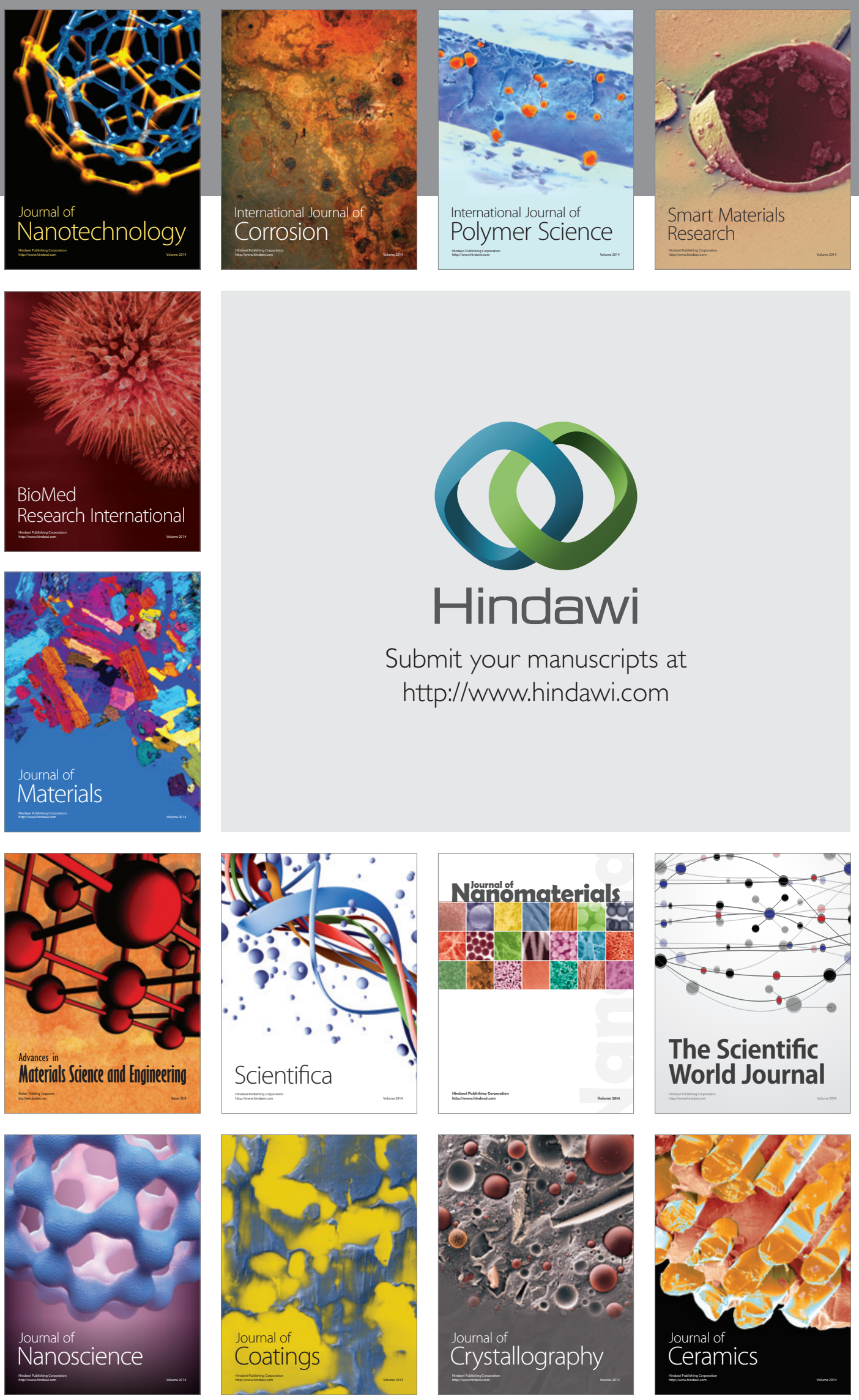

The Scientific World Journal

Submit your manuscripts at

http://www.hindawi.com

\section{World Journal}

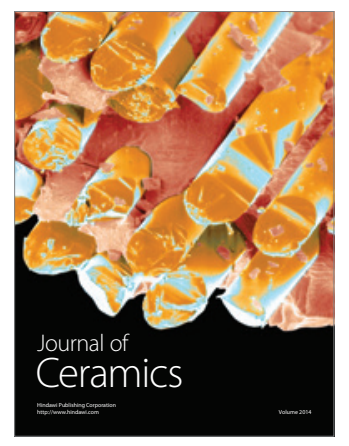

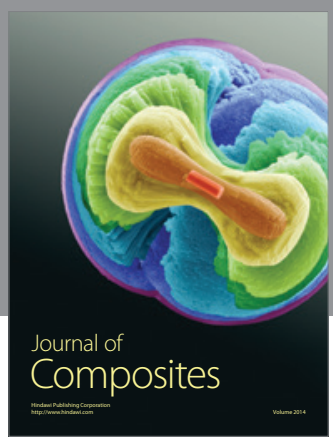
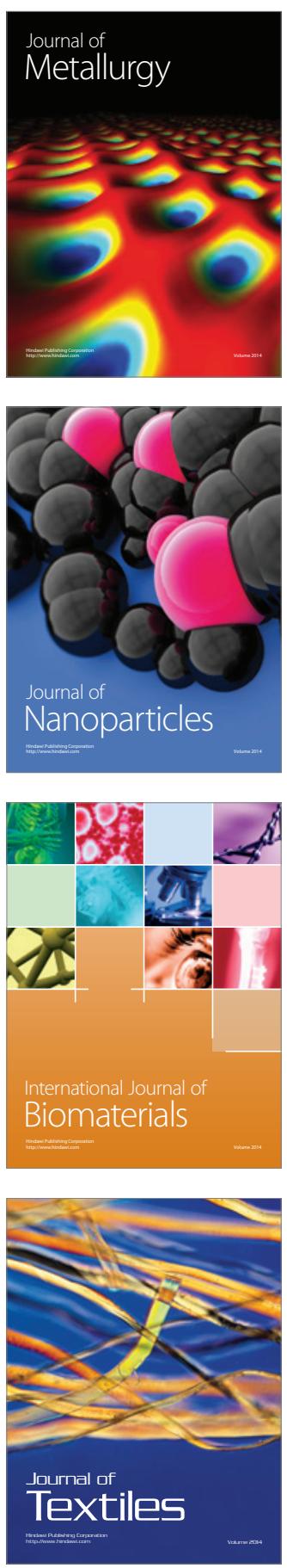